\title{
Zarzuela: ¿nom commun?*
}

“(L)a familiarité n'est pas la connaissance". François Jullien, L'écart et l'entre.

Este trabajo es el fruto de una pregunta y de varias observaciones. ¿Cuáles son las circunstancias y la evolución de la voz "zarzuela" en francés? Las definiciones proporcionadas por los diccionarios y la prensa musical en Francia y en España son muy diferentes. Antes de incorporarse al listado de palabras francesas, ya sea en diccionarios generales o especializados, el término "zarzuela" se empleaba en la prensa musical desde las primeras décadas del siglo XIX. Si en ambos casos la comparación con un género francés similar -la opéracomique-, aparece de forma sistemática, muchas de sus características desaparecen o se alteran a lo largo de la historia de la palabra en francés. El discurso que se elabora al respecto refleja un juicio estético, así como una percepción, desde el otro lado de la frontera, de un espectáculo que actúa como un símbolo español. Los autores aquí citados -desde periodistas y lexicógrafos al poeta Valery Larbaud o el escritor Gérard Genette, pasando por verdaderos aficionados a la zarzuela-, se apropian de la voz "zarzuela" y desarrollan un uso de este sustantivo que no llega a tener mucho en común con su homólogo español.

This article is the result of a question and several observations. What are the circumstances and the evolution of the term "zarzuela" in French? The definitions given in dictionaries and the musical press in France and Spain are very different. Prior to its incorporation into the list of French words, whether in general or specialised dictionaries, the term "zarzuela" was used in the musical press from the early decades of the nineteenth century. While in both cases the comparison with a similar French genre-opéra-comique- appears systematically, many of its characteristics disappear or were altered throughout the history of the word in French. The resultant discourse reflects an aesthetic opinion, as well as a perception, from the other side of the border, of a spectacle that serves as a Spanish symbol. The authors cited here-from journalists and lexicographers to the poet Valery Larbaud and the writer Gérard Genette, as well as true zarzuela aficionados-appropriated the term "zarzuela" and developed a use of this noun that did not have a lot in common with its Spanish counterpart.

Keywords: zarzuela, press, dictionary, nineteenth century, music theatre, lexicography.

Consultar un diccionario constituye un gesto cotidiano. Como tal, pocas veces se suele poner en cuestión el objeto consultado con tanta familiaridad. Por supuesto, si elegimos leer un artículo polémico de L'Encyclopédie de D'Alembert y Diderot, lo hacemos con los requisitos críticos, pero en lo cotidiano hay otros fenómenos en juego.

\footnotetext{
* Quiero agradacer a José María Domínguez su ayuda, correcciones y sugerencias en la redacción de este trabajo y a Emilio Casares, por hacer que, para mí, "zarzuela" sea un" "nom commun". Este trabajo ha sido realizado en el marco del proyecto I+D Música teatral en España: géneros, continuidades e interacciones (1680-1914). Ministerio de Economía, Industria y Competitividad (HAR2016-80768-P)..

${ }^{1}$ François Jullien: L'écart et l'entre. Leçon inaugurale de la Chaire sur l'altérité, París, Galilée, collection Débats, 2012, p. 13.
} 
Es habitual que el diccionario sea la referencia de la norma, un compendio de leyes que rigen el habla, y nos tranquiliza entenderla como algo fijo, inmutable y eterno. Esta creencia viene a chocar contra la realidad de la lengua, pero también con la actividad de los lexicógrafos y lexicólogos. La especialista Natalia Campos Martín nos ofrece una explicación muy aclaradora:

La lexicografia es un trabajo artesanal que exige una gran dosis de paciencia, pero también una ciencia que pertenece a la lingüística y la filología porque los lexicógrafos se esfuerzan en construir representaciones individualizadas del léxico de un idioma partiendo de los discursos observados. Son los verdaderos notarios del idioma ${ }^{2}$.

La metáfora final es muy potente y muestra el simbolismo patrimonial que motiva nuestra relación con nuestro idioma. De aquí el terremoto social cada vez que se anuncia una reforma de la ortografia ${ }^{3}$. De hecho, el punto de partida de este trabajo es un mero acento que vino a posarse sobre la voz francesa zarzuéla, algo parecido a lo que ocurrió con la voz opéra en el siglo XVII. Así pues, la palabra "zarzuela" aparecía en las listas de préstamos de un idioma extranjero en las Rectifications orthographiques $d u$ français, texto publicado en 1990 que enseguida fue considerado como una reforma, que en realidad no lo era, aunque tendiera a serlo. Copiamos la lista de términos afectados por un acento agudo:

\section{Rectifications orthographiques du français de 1990 (extrait)}

Mots empruntés à d'autres langues (liste G p. 15)

allégretto. allégro. braséro. candéla. chébec. chéchia. cicérone. condottière. décrescendo. diésel. édelweiss. impresario. kakémono. méhalla. pédigrée. pérestroïka. péséta. péso. piéta. révolver. séquoia. sombréro. téocalli. trémolo. zarzuéla

Añadir este signo típicamente francés implica, según el texto, la pérdida de signos exóticos y contribuye a homogeneizar la lengua francesa. Este proyecto liderado por la ilustre lingüista Nina Catach era el resultado de muchos años de reflexión sobre la mejora de la adquisición del idioma por

\footnotetext{
2 "La lexicographie est un travail artisanal qui exige une grande dose de patience mais aussi une science qui fait partie de la linguistique et de la philologie parce que les lexicographes s'efforcent de construire des représentations individualisées du lexique d'une langue à partir des discours observés. Ils sont les vrais notaires de la langue", Natalia Campos Martín, "Lexicographie et traduction (1): les différents types de dictionnaires: classements et typologie", Entreculturas, n. ${ }^{\circ}$ 1, 27-3-2009, p. 318.

${ }^{3}$ Sobre este tema, véase Elena Llamas Pombo: "Prestige normatif et diffusion des réformes orthographiques: les cas du français et de l'espagnol en contraste", L'orthographe en quatre temps. $20^{e}$ anniversaire des Rectifications de l'orthographe de 1990: Enseignement, recherche et réforme, quelles convergences? Actes du Colloque international de 2010, Susan Baddeley, Fabrice Jejcic y Camille Martinez (dirs.), París, Honoré Champion, 2013, 203-236.

${ }^{4}$ Journal officiel de la République Française, édition des documents administratifs, "Les rectifications de l'orthographe", année 1990, n. 100,6 -12-1990, pp. 15-17.
} 
parte de los alumnos en las escuelas francesas y, también, de los extranjeros. El equipo de Catach aconsejaba a los editores de diccionarios, a la academia francesa y al Ministro de Cultura emprender una reforma que reduciría la realidad sonora y visual, de ahí el acento sobre zarzuéla o paélia, además de introducir la vocal "i" para acercarse a la "ll" castellana. La verdad es que de todas las palabras que más llamaron la atención al público alertado por la prensa, "zarzuela" no iba a quitar el sueño a nadie -excepto a algunos musicólogos-, y no podía competir con la desaparición de la " $i$ " de oignon o del "ph" de nénufar. La falta de conocimiento sobre la elaboración de un objeto tan familiar como el diccionario hizo que nos preguntásemos qué intención había tras este hecho lingüístico. Porque como escribe el lingüista Jean-Marie Klinkenberg: "l'orthographe, c'est bien plus que l'orthographe"'5.

Para realizar esta investigación, nos hemos propuesto consultar varios tipos de diccionarios -generales, enciclopédicos y especializados- exclusivamente franceses. Al estar la voz "zarzuela" vinculada con la música, era imprescindible también revisar un tipo de prensa preocupada por la difusión del conocimiento musical. Para terminar, la presencia de la palabra "zarzuela" en obras literarias nos permitirá observar su uso en un medio presuntamente liberado de las normas que estructuran los textos didácticos.

Este recorrido a través del uso y la definición de la voz "zarzuela" en francés se organiza partiendo del eje de la norma: ¿cómo se materializa para este caso en concreto? ¿Por qué se transgrede?

El periodo se ha elegido en función de frecuencia de la palabra en los textos, por ello dedicamos mayor espacio al siglo XIX, y también se ha tenido en cuenta la realidad musicológica -sobre todo española ${ }^{6}$ - actual. Los términos se traducen, migran, se apropian, pero ¿evoluciona el objeto que designa al mismo ritmo? ¿Qué consecuencias acarrea la presencia de la voz "zarzuela" en los diccionarios, la prensa y la literatura francesa?

\section{¿El diccionario para solventar dudas?}

Aproximación a un objeto...

Si bien es una pena que ni la palabra "diccionario" ni "zarzuela" figuren en el satírico Dictionnaire des idées reçues de Flaubert, al menos contamos con estudios cada vez más numerosos sobre el proceso de hacer un

\footnotetext{
${ }^{5}$ Jean-Marie Klinkenberg: "Préface" L'orthographe, une norme sociale, Bernadette Wynants, Liège, Mardaga, 1997, pp. 5-8; 6.

${ }^{6}$ La existencia y la presencia en varias bibliotecas francesas del monumental Diccionario de la zarzuela, dirigido por Emilio Casares es reveladora.
} 
diccionario. Trabajos como los de Camille Martínez ${ }^{7}$ permiten descartar cierta dimensión ideológica en la manera en que se efectúa la elección, definición y actualización de los términos. Pero, a la vez, muestran cómo cada diccionario tiene su forma particular de difundir las normas. Siguiendo con los consejos redactados en las Rectifications, es interesante ver que hasta hace muy poco ningún diccionario las incluía en sus nuevas ediciones, por muy accesible y claro que sea este texto, pues nunca llegó a ser una reforma en el sentido estricto. Esta diversidad de criterios se suma a los distintos tipos de diccionarios que Natalia Campos estudia en su artículo. Traicionando los matices y el profundo conocimiento del terreno de la autora, solo aparecen las categorías siguientes: cosas/palabras; cantidad/ especialidad; bilingüe; e informatizado. Para investigar el destino de la voz "zarzuela" en los diccionarios franceses, excluimos el bilingüe.

Así, comenzamos con el diccionario de referencia online, el Trésor de la langue française informatisé, del cual reproducimos los epígrafes "etimología" y "lexicografia". En esta entrada, descubrimos que la voz "zarzuela" entra en la lengua francesa en 1904 mediante otro diccionario:

Étymol. et Hist. 1. 1904 art lyrique (Nouv. Lar. ill.); 2. 1984 art culin. (Courtine Gastr.). Mot esp. désignant une représentation dramatique mêlée de chants et une sorte de danse (dep. xvii ${ }^{\text {s. }}$., Lope deVega), dont le nom viendrait de celui du palais royal de la Zarzuela (v. Cor., s.v. zarza); désigne aussi un plat composé d'un mélange de fruits de mer, d'où 2 .

Lex.

- ART LYRIQUE. Pièce théâtrale lyrique espagnole où alternent le chant et la déclamation, comparable à l'opéra bouffe 8 .

Esta definición es interesante por dos razones: la primera parte establece cierta distancia en el discurso con la expresión sorte de y el condicional viendrait a propósito de sus orígenes. La parte lexicográfica recurre a la comparación con un género lírico que pertenece a la cultura del lector francés, l'opéra-bouffe. Para el musicólogo, esta última información no coincide con la realidad histórica del repertorio de la zarzuela, que, como bien indica la parte etimológica, empieza en el siglo XVII y se extiende mucho más hasta coincidir en la segunda mitad del siglo XIX con la ópera bufa. Quizá tenga que ver con el hecho de que según el TLFI, la voz "zarzuela"

\footnotetext{
${ }^{7}$ Véase Camille Martínez: L’orthographe des dictionnaires français: la construction de la norme graphique par les lexicographes, París, Champion 2012; Lorthographe en quatre temps $20^{e}$ anniversaire des Rectifications de l'orthographe de 1990. Enseignement, recherche et réforme, quelles convergences? Actes du colloque international de 2010, Susan Baddeley, Fabrice Jejcic et Camille Martinez (dir.), París, Champion, 2013.

${ }^{8}$ Centre National de Ressources Textuelles et Lexicales / Trésor de la langue française informatisé, acceso gratuito desde 2002, TLF, 1971-1994.
} 
no se incorpora al francés hasta 1904 , fecha muy tardía comparada con la de su nacimiento, pero también puede que esté relacionado con el conocimiento de esta en Francia, como veremos más adelante. El artículo del TLFI se refiere al Nouveau Larousse Illustré . En su último volumen, se puede leer lo siguiente:

ZARZUELA (zu-é - mot espagn.) n. f. Petit drame lyrique espagnol et portugais, où se mêlent le parlé et le chant.

Resulta sorprendente este error sobre la nacionalidad portuguesa de la zarzuela por parte de Claude Augé y sus colaboradores. Claude Augé era miembro de la familia de Pierre Larousse, fundador de uno de los dos principales diccionarios franceses, y conocedor tanto de la música como de la prensa musical que venía utilizando la voz "zarzuela" desde hacía bastante tiempo. En realidad, encontramos elementos didácticos sobre este género lírico español mucho antes en un artículo sobre la música en España, donde la voz "zarzuela" está citada, aunque no es el tema principal del artículo. Dirigida por Framery, Ginguené y De Momigny, la Encyclopédie méthodique de la musique está exclusivamente consagrada a la música, como anuncia su título, y es una obra de referencia en Francia para el siglo XIX. La enciclopedia "Pancoucke", como se suele llamar por su editor, prueba de su popularidad, expone lo siguiente en el párrafo sobre el teatro lírico en España:

La ópera seria, o gran ópera, se canta exclusivamente en italiano en el teatro de Madrid; pero se conoce desde hace mucho tiempo, como ya lo hemos visto, la comedia lírica en el idioma del país, idioma sonoro, poético y, por lo menos, tan musical como el italiano. Además del sainete, del cual he hablado ya, los españoles tienen la zarzuela, especie de drama lírico, más o menos similar a nuestras óperas cómicas, mezcla de prosa y canto; las escenas son simplemente declamadas, pero están entrecortadas por muchas arias, dúos, tríos y cuartetos, así como coros. Esta mezcla de lengua hablada y de lengua musical, por inverosímil que sea, no escandaliza más a los españoles que a nosotros, tanto es así que en las artes, como en las demás cosas humanas, la costumbre y la rutina imperan ${ }^{10}$.

\footnotetext{
${ }_{9}$ Claude Augé (dir.): Nouveau Larousse Illustré, París, Larousse, 1904, vol. 7, p. 1416.

10 "L'opéra sérieux, ou grand opéra, n'est chanté qu'en italien sur le théâtre de Madrid; mais on y connaît depuis longtemps, comme nous l'avons déjà vu, la comédie lyrique en langue du pays, langue sonore, poëtique, \& pour le moins aussi musicale que l'italienne. Outre la saynette dont j'ai parlé, les Espagnols ont la zarzuela, espèce de drame lyrique, à peu près semblable à nos opéras comiques mêlés de prose et de chant; les scènes y sont simplement déclamées, mais entrecoupées de beaucoup d'airs, de duos, trios, quatuors, \& même de chœurs. Ce mélange de la langue parlée \& de la langue musicale, quelque invraisemblable qu'il soit, ne choque pas les Espagnols plus que nous, tant dans les arts comme dans les autres choses humaines, l'habitude \& la routine ont d'empire [...]". M. Ginguené: "Espagne", Encyclopédie méthodique de la musique, Framery, Ginguené y De Momigny (dirs.), París, Pancoucke, vol. 1, 1791, pp. 520-524.
} 
Observamos una vez más el uso prudente de "especie de", pero formulamos la hipótesis de que, en esta época, tal uso se podía interpretar como "variedad de" y no como objeto indefinido como entendería el lector de hoy. El autor del artículo, Ginguené, también recurre a la comparación usando la fórmula "similar a": la zarzuela formaría parte de la misma "especie" que la ópera cómica francesa. Para fortalecer la similitud, propone un comentario estético. Segun él, el español es una "lengua sonora, poética y [...] musical", vinculando su propuesta a los debates del siglo XVIII en torno a Rousseau. Señala también que el público francés y el español aprecian y no se extrañan de la "mezcla" de lo hablado con lo cantado, rasgo definitorio del género de la zarzuela desde su origen hasta nuestros días.

Si leemos una definición más actual, como la del Dictionnaire historique de la langue française, vemos que es muy parecida:

Zarzuela: s.f., extranjerismo español (1904) donde se emplea desde el siglo XVII y tiene probablemente su origen en el nombre del Palacio Real de la Zarzuela.

La palabra designa una pieza lírica española mezclada con diálogos y cantos, vecina de la ópera bufa o de la opereta ${ }^{11}$.

Doscientos años aproximadamente separan las dos definiciones y, a pesar de la idea que hoy tenemos de la zarzuela, aun desde Francia y dentro de un diccionario no especializado en música, casi podríamos decir que la más antigua de las dos es la que mejor define el género. De hecho, la fórmula sans doute "sin duda, probablemente" -que en francés indica que sí hay una duda- muestra una prudencia inútil. Si de algo estamos seguros es de que el origen de la palabra zarzuela está en el Real Sitio del mismo nombre.

El único diccionario en francés que define la zarzuela como "género de ópera cómica española" (y con la ortografia rectificada, es decir con la tilde), es el diccionario colaborativo online Wiktionnaire ${ }^{12}$, pero surge una duda: ¿debemos entender género como etiqueta o categoría o es sinónimo en francés de "especie de"?

${ }^{11}$ Alain Rey (dir.): Dictionnaire historique de la langue française, $3 .^{a}$ ed., 2 vols., París, Dictionnaires Le Robert, 2000 (1. ${ }^{a}$ ed. 1992).

Zarzuela: nf est un emprunt (1904) à l'espagnol où le mot s'emploie depuis le $17^{\text {e }}$ et vient sans doute du nom du Palais Royal de la Zarzuela

Le mot désigne une pièce lyrique espagnole mêlée de dialogues et de chants, voisine de l'opéra bouffe ou de l'opérette.

${ }^{12}$ Wiktionnaire, "zarzuéla", genre d'opéra comique espagnol (https://fr.wiktionary.org/wiki/zarzuela; consulta 24-10-2018). 


\section{... u objeto de aproximación}

Hubiéramos podido pensar que esta aproximación, con su falta de rigor y de conocimiento, tenía que ver con el carácter generalista de los diccionarios franceses consultados. Sin embargo, llegamos a una conclusion similar al leer la entrada de un diccionario especializado en música como el de Marc Vignal. La definición de "zarzuela" es la misma desde 1997:

Zarzuela: Forma particular de España de teatro popular acompañado de música y de canto. Durante mucho tiempo subalterna, hasta olvidada, esta tradición alzó el vuelo de forma fulminante alrededor de 1860. La zarzuela se emparenta entonces con el teatro satírico, casi cancioneril, y va a buscar su música en las coplas populares que corren por la calle $[\ldots]^{13}$.

Se entiende que este tipo de diccionarios tenga entre sus misiones la divulgación de los términos musicales. Pero, si bien se repiten ciertos esquemas como la aproximación con la fórmula "alrededor de", que corresponde a los años que rodean la inauguración en 1856 del Teatro de la Zarzuela en la calle Jovellanos, nos llama la atención el supuesto conocimiento acerca de su carácter exclusivamente popular que reduce o, más bien, concentra la historia del género a la segunda mitad del siglo XIX. Lo más sorprendente en este tipo de diccionarios es la subjetividad presente en la personificación de las "coplas que corren por las calles" y la elección de la palabra fredons, con un matiz algo peyorativo, que podríamos traducir como "tarareos".

De este enfoque al de un diccionario liberado de las convenciones y reglas solo hay un paso. Son muchos los diccionarios que dan vía libre a una afición personal. Así, existe una colección, difundida por la editorial de "diccionarios amorosos", de la que forma parte el Dictionnaire amoureux de l'Espagne, a cargo del autor hispanófilo Michel Castillo. Esta obra contiene su propia entrada de "zarzuela", de la que reproducimos una parte:

Zarzuela: una opereta, un vodevil cantado y hablado que goza, al final del siglo XIX y al principio del XX, de un entusiasmo popular extraordinario [...]. La ciencia musical no es suficiente para escribir una buena zarzuela; hay que poseer este talento raro que sabe unir la ligereza con la fantasía desenfrenada. Nada es más difícil que componer, sin ceder a la vulgaridad, música popular. Sin embargo, la zarzuela es para España lo que la buena canción popular es para Francia, no un género menor, sino un género a secas. ${ }^{14}$

13 "Forme particulière à l'Espagne de théâtre populaire accompagné de musique et de chant. Longtemps subalterne, voire oubliée, cette tradition prit soudain un essor foudroyant aux alentours de 1860 . La zarzuela s'apparente alors au théâtre satirique, voire chansonnier, et va chercher sa musique dans les fredons populaires qui courent les rues [...]". "Zarzuela", Marc Vignal (dir.): Dictionnaire de la musique, París, Larousse, 1997

14 "Une opérette, un vaudeville chanté et parlé qui jouit, à la fin du XIXe siècle et au début du XXe, d'un engouement populaire extraordinaire [...]. La science musicale ne suffit pas pour écrire une bonne 
Si también Castillo parece reducir la zarzuela a su carácter "popular", citando obras como La verbena de la Paloma, al contrario que en el artículo del Dictionnaire de la musique, aparece aquí revalorizada, rehabilitada. De hecho, unas líneas después, insiste en ello: "Dans ses meilleures pages, la z imite si bien le genre noble qu'on ne sait plus très bien les distinguer".Y, por fin, después de señalar la "zarzuela" como un "género", termina con una última frase a modo de definición: "La zarzuela, c'est le plaisir naïf de cet abandon". Si la postura es personal, subjetiva, como permite la orientación de su diccionario, nos encontramos con un defensor del género que, aún más en francés que en castellano, podría ser calificado de "aficionado". Teniendo en cuenta estas consultas se constata la paradoja siguiente: para acercar el objeto al lector, es preferible una definición tan simplificada que resulta errónea. En todo caso, hemos observado, si no descubierto, que ninguna de estas definiciones francesas es neutral ni satisfactoria.Y, como se ha podido evidenciar, ninguna de ellas corresponde a la traducción de la voz "zarzuela" de cualquier diccionario usual de castellano.

No siempre encontramos lo que buscamos en el sitio esperado. Precisamente es lo que pretende Gérard Genette con su sorprendente diccionario Bardadrac. El gran teórico de la hermenéutica, el autor de las tan consultadas Figures, se marcó como programa concebir un "répertoire de mots et catalogue de choses". La obra se aproxima a un diccionario, aunque Genette advierte a su lector que encontrará "épiphanies contingentes, idées bonnes ou mauvaises, souvenirs vrais et faux, partis pris esthétiques", apartándose de la objetividad que se presupone de diccionario tradicional. Está de este modo, libre de prejuicios o de idées reçues, que el lector descubre en su artículo "zarzuela":

Es el nombre, muy conocido, de una casa de campo cerca de Madrid donde reside mi reina favorita, pero también de un género, siempre sabroso, de opereta u ópera bufa típicamente hispánico, que sobrevivió y sobrevivirá quizás a varios siglos de modas y contra-modas, y también de una sala de teatro madrileña más o menos exclusivamente dedicada a este género [...], tan típicamente española como el albergue que de esta forma se denomina [i.e., l'auberge espagnole] y donde solo se encuentra lo que allí se lleva ${ }^{15}$.

\footnotetext{
zarzuela; il faut posséder ce talent rare qui sait allier la légèreté à la fantaisie débridée. Rien n'est plus dur que de composer, sans céder à la vulgarité, une musique populaire. Or, la zarzuela est à l'Espagne ce que la bonne chanson populaire est à la France, non un genre mineur, mais un genre tout court", Michel Castillo: Dictionnaire amoureux de l'Espagne, Plon, 2005.

15 "C'est le nom bien connu d'une maison de campagne proche de Madrid, où réside ma reine préférée, mais aussi d'un genre, toujours savoureux, d'opérette ou d'opéra-bouffe typiquement hispanique, qui a survécu et survivra peut-être à quelques siècles de modes et de contre-modes, et encore d'une salle de théâtre madrilène plus ou moins exclusivement consacrée à ce genre (...) aussi typiquement espagnol que l'auberge ainsi qualifiée, où l'on ne trouve que ce qu'on y apporte", Gérard Genette: Bardadrac, París, Seuil, Points, 2006, p. 572. Con la expresión "auberge espagnole", procedente de la mala fama que tenían las fondas españolas entre los extranjeros desde el siglo XVII, se designa un lugar donde hay de todo o todo tipo de gente.
} 
A pesar del tono voluntariamente ligero (el título Bardadrac ya era en sí un aviso) ${ }^{16}$, el artículo repite elementos de fondo esperados: el origen y la comparación. Además de destacar el hecho de que la palabra "género" sea utilizada, lo que, como hemos visto, no ocurre en la mayoría de los artículos, Genette observa la zarzuela con una mirada propia muy reflexiva. Su manera de definir el género es abierta y llena de perspectivas, como si el elemento definido fuese la proyección de quien escribe y quien lee, es decir, un verdadero encuentro. No cabe duda de que a cualquier conocedor de la zarzuela le agradaría este planteamiento y, sobre todo, el gesto significativo, por ser Genette, de la elección de la palabra, que se convierte en todo un homenaje.

\section{La zarzuela real y sus presuntos títulos}

No podíamos dejar de incluir en nuestro balance un tipo de diccionario aún más específico como son los diccionarios catálogos. El trabajo de los directores consiste en establecer una lista lo más completa posible de todos los títulos que pertenecen a un género. El caso del Dictionnaire des opéras de Clément y Larousse, publicado por primera vez en 1869, refleja la realidad de la zarzuela a través de sus títulos. Aunque solo es posible una búsqueda por palabra clave en la versión digital, ya que los títulos siguen el orden alfabético, la búsqueda manual por título es imprescindible para obtener un resultado más completo ya que, en este caso particular, muchas zarzuelas han perdido su título y muchos títulos han perdido su género. Hemos organizado los datos según las distintas categorías que designaban títulos de obras vinculadas con la zarzuela:

Cuadro 1. Categorías empleadas en el Dictionnaire des opéras de Clément et Larousse ${ }^{17}$

\begin{tabular}{|c|c|c|c|}
\hline $\begin{array}{l}\text { Opéra-comique appelé } \\
\text { en Espagne zarzuela }\end{array}$ & Opéra-comique espagnol & Zarzuela & Zarzuela espagnole \\
\hline $\begin{array}{l}\text { Fexia di Santi-Ponce (la) } \\
\text { Soriano Fuertes c. } 1842 \\
\text { Geroma la Castaneca } \\
\text { (Geroma la joueuse de } \\
\text { castagnettes) en } 1 \text { acte, } \\
\text { musique de SF Madrid } \\
\text { c. } 1840 \\
\text { Ventorrillo de Alfarache (Il) }\end{array}$ & $\begin{array}{l}\text { El amor enamorado, musique } \\
\text { de Arrieta } 1880 \\
\text { Jugar con fuego (jouer avec le } \\
\text { feu), Cirque } 1851 \\
\text { Margarita musique de C. } \\
\text { Moderati joué à la Z de } \\
\text { Madrid en avril } 1864 \\
\text { Tio Camgitao (El), musique } \\
\text { de Soriano Fuertes }\end{array}$ & $\begin{array}{l}\text { Belan van los zagales }(A) \\
\text { musique de Soriano Fuertes } \\
\text { Cordoue ca. } 1844 \\
\text { Primer día feliz (El) musique } \\
\text { de Fernández Caballero } \\
\text { représentée à Madrid en } \\
\text { janvier } 1872\end{array}$ & $\begin{array}{l}\text { Ildara, musique de M. } \\
\text { Cristobal Oudrid, } \\
\text { représentée sur le théâtre } \\
\text { de Jovellanos à Madrid en } \\
\text { janvier } 1874\end{array}$ \\
\hline
\end{tabular}

16 También podemos citar otro diccionario de este tipo con un tono similar, pero consagrado integralmente a la zarzuela: Pierre-René Serna: Guide de la zarzuela ou l'opéra-comique espagnol de Z à A, 2012.

${ }^{17}$ Hemos conservado la ortografía del diccionario con sus múltiples errores que consideramos relevantes. 


\begin{tabular}{|c|c|c|c|}
\hline Opéra espagnol & Opéra & Opérette espagnole & $\begin{array}{c}\text { Scène dramatique } \\
\text { espagnole }\end{array}$ \\
\hline 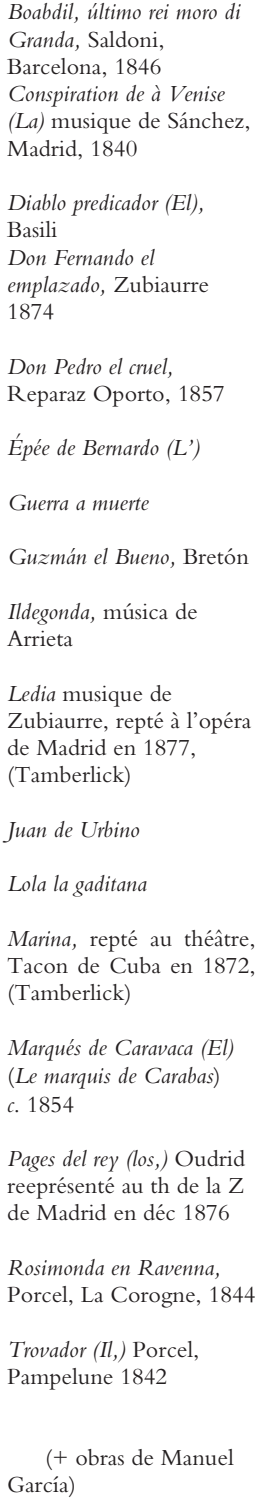 & $\begin{array}{l}\text { Adela di Lusignano } \\
\text { Colombo, música de Carnicer } \\
\text { Dominó azul (El) en trois } \\
\text { actes repté au théâtre d'oc } \\
\text { espagnol de Madrid en } 1852 \\
\text { Don Juan Tenorio, Carnicer } \\
\text { Estrella de Madrid (La) en } \\
\text { trois actes représenté à l'oc } \\
\text { espagnol } \\
\text { Elena y Constantino } \\
\text { Eufemio di Messina } \\
\text { (Ipermestra, opera italien de } \\
\text { Carnicer) }\end{array}$ & $\begin{array}{l}\text { Tio Canillitas, Soriano } \\
\text { Fuertes }\end{array}$ & $\begin{array}{l}\text { Naves de cortes, musique de } \\
\text { Chapí, } 1874 \text {, opéra de } \\
\text { Madrid }\end{array}$ \\
\hline
\end{tabular}


Podemos apuntar varios elementos. El más llamativo es la poca productividad de la voz "zarzuela", mientras que la mayoría de sus títulos más famosos se encuentran en la categoría “ópera española”. Entre estos están El Marqués de Caravaca y L'Épée de Bernardo de Barbieri, mientras que en la categoría "ópera" aparece El dominó azul, que en realidad son tres zarzuelas famosas de autores conocidos. Quizás fueron consideradas como "óperas" por su número de actos, pero sobre todo por desarrollar una intriga de corte, como también es el caso de Jugar con fuego, considerada como "opéracomique espagnol" en este catálogo. Además de emplear un criterio poco uniforme, es de destacar el ínfimo número de títulos de zarzuela o de ópera en español.

La presencia y las definiciones de la voz "zarzuela" en distintos diccionarios franceses no reflejan la naturaleza del género, que parece ser muy desconocida. Cuanto más nos alejamos de las exigencias normativas de los diccionarios, usuales o especializados, es cuando mejor nos acercamos a esta realidad, eso si, al precio de la subjetividad.

\section{“Zarzuela" en la prensa: de la definición a la afición}

No solo los diccionarios tienen como meta aportar información sobre las palabras, también es la función de cierta prensa y, en nuestro caso, la prensa musical. Hemos eligido un periódico representativo de este movimiento, Le Ménestrel, publicado por primera vez en París en 1833. Por su orientación, más centrada en el arte lírico que la Revue et Gazette Musicale de Paris, resulta ser un terreno fértil para nuestra búsqueda. En efecto, el lector pudo encontrar la palabra zarzuela desde el año 1839 en un artículo didáctico, dedicado a la música en España:"Les Espagnols ont en outre la zarzuela, sorte de drame lyrique qui ressemble beaucoup à l'opéra-comique" 18 .

Como cabe esperar, el estilo es muy próximo al de un artículo de diccionario, pero el formato permite a los autores un mayor desarrollo del concepto, en tanto en cuanto se presentan las obras en medio de un contexto estético y cultural.

\section{Glosas y diferencias}

El Ménestrel también tiene como papel anunciar y comentar los eventos musicales en París, en provincias y en el extranjero. La actualidad de una cantante como Madame Ugalde siempre tiene repercusión, aún más cuando hay alguna novedad como es la zarzuela, según el autor de un artículo de 1859:

\footnotetext{
18 "La musique en Espagne”, Le Ménestrel, n. 304, 29-9-1839, p. 1.
} 
En último lugar, Madame Ugalde ha realizado una verdadera proeza. Con solo saber algunas palabras en español, ha aprendido y representado una ópera cómica española, una zarzuela, como se dice en Madrid, del señor don Joaquín Gaztambide: El estreno de una artista. Se sabe que la zarzuela es la ópera cómica española ${ }^{19}$.

Para nuestro trabajo, el elemento lingüístico es interesante, sobre todo el uso de palabras es castellano como "señor", así como la comparación de un género con otro. También podemos pararnos a pensar sobre la expresión "comme on dit à Madrid". El autor parece preocupado por reproducir lo más fielmente - ¿objetivamente?- posible el contexto (Madrid y una obra de Gaztambide) en el cual se usa la palabra. Son muchas las recurrencias de este tipo aunque no las reproduzcamos aquí.

En un artículo de 1869, surge otra forma de tratar el término al hablar de datos estadísticos. Comentando el número de obras líricas representadas en España para esa temporada, podemos acceder a la siguiente información: de 948 óperas, se habían representado 2.596 vaudevilles (zarzuelas) y 4.953 obras dramáticas ${ }^{20}$.

Como vemos, la voz "zarzuela" aparece entre paréntesis como traducción o al menos equivalente al vaudeville.

Por supuesto, la presencia de nombres de compositores también está implicada en la presencia de la palabra: “¿Qué hay pues de vosotros, Barbieri, Gaztambide y vosotros todos, alegres trovadores de la zarzuela?" 21.

La pregunta suena nostálgica con la palabra trouveres y su connotación medieval, o por lo menos antigua, como si con Barbieri y Gaztambide estuvieran borrando una etapa de la historia de la zarzuela para dar paso a otra menos apreciada. En la década siguiente nos topamos con un tono parecido, pero aún más amargo, bajo la pluma del crítico español Antonio Peña y Goñi, quien colaboraba con el periódico francés: "nuestra ópera cómica autóctona, perdonadme la palabra, está acabada, y bien acabada" 22 .

La consulta sistemática del periódico atestigua el hecho de que la "zarzuela" se consideró acabada duró varias décadas. Es el caso de Raoul Laparra, autor él mismo de zarzuelas en francés, que, en 1925, deplora la mala influencia de la opereta, "degenerando” el género. Según Laparra, el éxito de obras como La montería, Los Gavilanes, Doña Francisquita, Don Quintín el

19 Gustave Bertrand: “Opéra-Comique': En dernier lieu, Mme Ugalde a fait un véritable tour de force. Ne sachant que quelques mots d'espagnol elle a, de la veille au lendemain, appris et joué un opéra-comique, una zarzuela, comme on dit à Madrid, du señor D. Joaquin Gaztambide: El estreno de una artista.On sait que la zarzuela est l'opéra-comique espagnol", Le Ménestrel, 28-8-1859.

${ }^{20}$ Le Ménestrel, 14-8-1869.

21 "Nouvelles diverses. Étranger" "que devenez-vous donc, Barbieri, Gaztambide et vous tous, joyeux trouvères de la zarzuela?", Le Ménestrel, 24-12-1876, p. 5.

22 "Notre opéra-comique indigène, passez-moi le mot, notre zarzuela, est finie et bien finie", Le Ménestrel, 20-1-1889, p. 4. 
amargao, La canción del olvido o La linda tapada muestra la decadencia de la "zarzuela nacional": "en efecto, la opereta ya dejó huellas incontestables en obras célebres en España y que solo tienen de zarzueliano la denominación"23. Para el lexicólogo, la producción del adjetivo zarzuelien (zarzuelero) podría considerarse un fenómeno interesante. Muestra la voluntad, una vez más, de ofrecer una definición lo más cercana posible a la realidad del repertorio por parte de un conocedor. En estas fechas, ya no es suficiente comparar -en general- positivamente la zarzuela con la ópera cómica francesa: hay que añadir la mala compañía de la opereta para valorar su casticidad. En el mismo número, otro conocedor de la música española, Henri Collet, en su intento de escribir la historia del género, lo asocia a la ópera cómica, incluso si para ello hay que negar un siglo de historia y entender la zarzuela como consecuencia y no como género original:

Las Labradoras de Murcia, representada en 1769 en el Teatro del Príncipe, son el fruto notable de la colaboración de Hita y Ramón de la Cruz. Marcan una fecha en la historia de la música nacional y contestan "a la española" al desafío lanzado desde Francia por Philidor, Monsigny y Grétry. Estamos ante la verdadera ópera cómica española, popular, pintoresca, con ritmo de danza (hasta una jota murciana), zumbado de guitarras, de mandolinas, de tambores vascos y castañuelas, todo en alegres canciones, en coros animados y llenos de colores ${ }^{24}$.

Son muchos los términos que subrayan el carácter español y nacional de la zarzuela que, aunque no deben sorprendernos en esta época, enfatizan su costumbrismo hasta un lirismo exagerado. El calificativo "verdadera" es equívoco: significa tanto auténtico como exclusivo. Este último significado se asocia al ejemplo anterior: el discurso sobre la definición de la zarzuela es un buen instrumento para medir una visión nacionalista de la música.

Con este mismo significado del adjetivo "verdadero", en otro artículo de 1930, el mismo autor comenta el origen de la palabra zarzuela, tras citar a Subirá y a Barbieri: "Es exacto que esta palabra viene de zarza que designa un enredo de bejucos $[\ldots]$. En realidad, 'zarzuela' significa 'ópera cómica'”. 25

\footnotetext{
23 "En effet, l'opérette a déjà des traces incontestables dans des œuvres célèbres en Espagne et qui n'ont de zarzuelien que l'appellation.", Raoul Laparra: "Mouvement musical à l'étranger. Espagne", Le Ménestrel, 28-8-1925, p. 9.

24 "Les Laboureurs de Murcie, joués en 1769 sur le théâtre du Principe, sont le fruit remarquable de la collaboration de Hita et Ramón de la Cruz. Ils marquent une date dans l'histoire de la musique nationale et répondent "à l'espagnole" au défi lancé de France par Philidor, Monsigny et Grétry. Nous sommes en présence du véritable opéra-comique espagnol, populaire, pittoresque, rythmé de danses (voire d'une jota murciana), bourdonnant de guitares, de mandolines, de tambours de basque et de castagnettes, tout en joyeuses chansons, en chœurs vivants et colorés". Henri Collet: "La musique espagnole" Le Ménestrel, pp. 7-8.

25 "Il est exact que ce mot vient de zarza qui désigne un enchevêtrement de lianes [...]. En réalité, "zarzuela" veut dire "opéra-comique". Henri Collet, "Le mouvement musical à l'étranger. Espagne", Le Ménestrel, 17-10-1930, p. 10.
} 
Los términos "es exacto" y "en realidad" muestran, por un lado, la búsqueda de la precisión por parte de un experto francés, pero, por otro lado, la voluntad de apropiarse del objeto, que ya era francés desde 1904 según hemos visto, envolviéndolo con la promesa de la verdad.

\section{"Zarzuela": la tentación de la ficción y la construcción de un personaje}

Bajo la pluma de Laparra y Collet, la zarzuela aparece como un personaje de su propia ficción. En otro artículo sobre la historia del género, Laparra, fingiendo dirigirse a las tonadillas, escribe:

Y bien, vuestra hermana, la Zarzuela, es como vosotras. Lo he visto, una vez más, durante la visita que acaba de hacernos: todas las veces que se convierte en guitarra y se flamenquiza es una estocada en el corazón y el entusiasmo, pero cuando se mezcla de influencia extranjera, ¡cómo se vuelve todo espeso, ay, y pueril! [...]. Si la Zarzuela se vuelve sublime, será por accidente y sin intervención. Es una chula ligera que puede tener sus penas, por supuesto. Pero, entre nosotros, ¡bien sabéis cómo tiene sus penas, la chula! No las declamará, sino que las cantará, y a menudo riéndose, porque cantando "las lágrimas no se derraman"26.

La promoción de la zarzuela pasa por el rechazo de lo extranjero y su personificación: la zarzuela es española, como la chula. Por muy lírica que sea, esta visión goyesca y bastante anticuada es anacrónica para un género que en estos años triunfaba, en realidad, a través de múltiples caras, desde la opereta a la revista.

Collet procede a un retrato similar al comentar la temporada de 1927 del Teatro de la Zarzuela, que se inició con una obra extranjera provocando que "todas las majas de la obra zarzuelera esperaran a la puerta para que las dejen entrar en su casa" 27 .

La voz "zarzuela" es fantasmagórica en dos sentidos: parece referirise a un género muerto del cual ha sobrevivido el recuerdo, pero también se puede considerar un fantasma, si lo entendemos como un deseo: el de un género nacional que se conforma según criterios basados en una mirada hacia el pasado. Esta mirada suena como su condena cuando en 1930, en un artículo ya citado, Collet informa de un proyecto de Ricou y Masson

26 "Et bien votre sœur, la Zarzuela, est comme vous. Je l'ai, une fois de plus, réalisé, durant la visite qu'elle vient de nous faire : toutes les fois qu'elle redevient guitare et flamenquise, c'est l'estocade au coeur et l'enthousiasme, mais quand elle se matine d'influence étrangère comme ça devient épais hélas et puéril! [...] Si elle devient sublime, la Zarzuela, ce sera par accident et sans intervention. C'est une chula légère qui peut avoir ses peines, évidemment. Mais, entre nous, vous savez bien comment elle les a, ses peines, la chula! Elle ne les déclamera pas, mais elle les chantera, et souvent en riant, parce qu'en chantant "les larmes ne sortent pas". Raoul Laparra "Le mouvement mucial à l'Étranger. Espagne", Le Ménestrel, 23-7-1926, p. 10.

27 "Et l'on a inauguré la saison d'opéra à la zarzuela, en décembre par... une œuvre étrangère. Et toutes les exquises majas de l'œuvre zarzuelienne attendant à la porte que l'on veuille bien les laisser rentrer chez elles", Henri Collet, Le Ménestrel, 22-4-1927. 
de representar una zarzuela, lo que equivaldría a "restituir la antigua ópera cómica"28.

Esta obsesión en la prensa musical francesa de los años 20 y 30 del siglo XX por asociar "zarzuela" y siglo XIX con una figura animada puede interpretarse como la herencia de otro fantasma más conocido: la visión romántica de España.

\section{Objeto literario}

Exótico

El siglo XIX se caracterizó por la difusión masiva en la prensa de conocimientos procedentes del extranjero, lo que favoreció los trabajos especializados e históricos. De forma paralela, en Francia, España adquiere una imagen romántica, es decir, literaria e imaginaria, que perdura mucho más allá del Romanticismo y del Viaje a España de Théophile Gautier ${ }^{29}$. El caso de alguien como La Laurencie es extremadamente elocuente. Junto con Albert Lavignac, dirigió un trabajo de referencia en el ámbito musicológico como es la Encyclopédie de la musique et dictionnaire du conservatoire ${ }^{30}$. Las páginas sobre la música en España estuvieron a cargo de Rafael Mitjana quien, como se puede imaginar, controlaba perfectamente los matices entre los distintos géneros líricos. El mismo Lionel de la Laurencie había publicado varios años antes un ensayo sobre España a modo de relato de viaje, en el cual la vida musical madrileña ocupaba varias páginas. Copiamos su definición de la zarzuela:

La zarzuela es una mezcla de coplas, en general tomadas de las melodías populares, de coros y diálogos hablados en el género bufo. El principio de composición es, como se observa, más o menos el mismo que el de nuestras operetas y nuestros vodeviles. Pero la zarzuela presenta este carácter muy particular y esencial de representar solamente al pueblo y las costumbres populares ${ }^{31}$.

\footnotetext{
28 "Par suite, MM. Ricou et Masson, s'ils montent jamais une "zarzuela", ne feront autre chose que de nous restituer l'ancien opéra-comique [...]. Dans cet ordre d'idées, Subira note qu'on peut citer nombre de partitions pleines de verve, d'ingénuité et de grâce, et dédaignant les complications excessives de l'écriture", Henri Collet: "Le Mouvement musical à l'étranger. Espagne", Le Ménestrel, 17-10-30, p. 10.

${ }^{29}$ Sobre este tema, véase Carlos Serrano: El nacimiento de Carmen. Símbolos, mitos y nación, Madrid, Taurus, 1999; y Adolfo Salazar: "España país romántico", El siglo romántico, Madrid, Yagües, 1936.

${ }^{30}$ Albert Lavignac, Lionel de La Laurencie (eds.): Encyclopédie de la musique et dictionnaire du conservatoire. Première partie, Histoire de la musique, Espagne, Portugal, París, Librairie Delagrave, 1920.

31 "La Zarzuela est un mélange de couplets, généralement empruntés aux mélodies populaires, de choeurs et de tirades parlées dans le genre bouffe. Le principe de composition est, on le voit, à peu près le même que celui de nos opérettes et de nos vaudevilles. Mais la Zarzuela présente ce caractère très particulier et essentiel qu'elle ne met en scène que le peuple et les costumes populaires", Lionel de La Laurencie: España. Simples esquisses, París, Alphonse Lemerre, 1890, p. 201.
} 
El paralelismo entre el genre bouffe, l'opérette o los vodeviles centra la "zarzuela" en la segunda mitad del siglo XIX, es decir, en el repertorio contemporáneo al autor, y no en su periodo. Una vez más, el carácter popular parece exclusivo. La Laurencie va más allá y escribe que no hay "reyes de fantasía" en la zarzuela, es decir, que el género solo pondría en escena argumentos relacionados con el pueblo, lo que desmienten numerosas zarzuelas, entre ellas las más famosas, cuya trama está centrada en la corte. Si bien es cierto que reconoce el talento de Arrieta y Bretón, considera su música como "llena de gracia y viva, que no deja de ser género chico" 32 . Aunque no podemos dejar de establecer un vínculo con la denominación "género chico", no es suficiente para justificar el poco conocimiento del autor francés.

Otro ejemplo es el de Ernest Martinenche, ilustre filólogo francés, profundo conocedor y promotor de la cultura española. Sus ensayos siguen siendo emblemáticos para todos los investigadores interesados en los estudios en francés sobre España o las relaciones entre los dos países ${ }^{33}$. En su texto Propos d'Espagne expresa libremente sus recuerdos y su visión del país, dedicando varias páginas a la música y, en particular, a la zarzuela: "Mientras tanto, no es en el Teatro Real donde conviene buscar la verdadera tradición musical de España. La encontraremos en los teatros dedicados al 'género chico', en el sabor que, a veces, se inspira en la música popular de las 'zarzuelas"' 34 .

Si consideramos su "propuesta" como un artículo de diccionario, la zarzuela podría definirse como "verdadera tradición musical de España", anteponiendo el juicio del autor a la descripción técnica. En realidad, las dos cosas no son excluyentes como podemos ver unas páginas más adelante:

La zarzuela toma el sitio en España, y con mucha ventaja, del café-concierto. Es muchas veces inepta, no es nunca tonta de capirote [...]. Pero no es, como en otras partes, el arte fácil de hacer perder una hora o dos. Atrayendo a los españoles, y prácticamente a todos los españoles, tiene que satisfacer los gustos más vivos y los más generales, y le incumbe a ella, aún más quizás que a las grandes obras, revelarnos estos gustos hoy ${ }^{35}$.

\footnotetext{
32 "Musique gracieuse et vive qui reste toujours de la petite musique". Ibid., p. 209.

33 Entre ellos destacamos Ernest Martinenche: L' Espagne et le romantisme français, París, Hachette, 1922.

34 "En attendant, ce n'est point au Teatro Real qu'il convient de chercher la véritable tradition musicale de l'Espagne. Nous la retrouverons dans les théâtres consacrés au 'petit genre', dans la saveur que tire parfois de l'inspiration populaire la musique des 'Zarzuelas'”, Ernest Martinenche: Propos d'Espagne, París, Hachette, 1905, p. 175

35 "La zarzuela remplace en Espagne, et fort avantageusement, le café-concert. Elle est souvent inepte, elle n'est jamais bête à pleurer. [...]. Mais elle n'est pas seulement, comme ailleurs, l'art facile de faire perdre une heure ou deux. Attirant les Espagnols, et presque tous les Espagnols, il faut qu'elle satisfasse leurs goûts les plus vifs et les plus généraux, et c'est à elle, plus encore peut-être qu'aux grandes œuvres, de nous les révéler aujourd'hui". Ibid., p. 187.
} 
Antes de comentar la parte más interesante de este estudio, cabe recordar que no es el único en adoptar este tono familiar y depreciativo, aun cuando lo que sigue es un elogio. También Raoul Laparra escribía desde Sevilla algo similar en 1928 para Le Ménestrel: "No es más tonta la música de estas zarzuelas que muchas cosas nuestras. Es incluso superior en el estilo a nuestras operetas y suena mejor la orquesta. Pero los libretos son muchas veces el colmo de la estupidez"36.

Descubrimos una nueva analogía, esta vez con el café concierto, pero sobre todo descubrimos cuánto valoraba Martinenche el género, hasta el punto de reflejar el gusto español, aunque fuera porque no se asimila a grandes obras. El autor termina explicando su teoría, en la cual se distingue su España ideal:

Alternativamente novelesca y realista, satírica con fineza, y grotesca hasta la grosería, la zarzuela de hoy nos presenta, en los contrastes que cuida, el espejo borroso del antiguo genio español. Es ciertamente raro que tenga un valor artístico, y nunca animamos demasiado a los que, como los hermanos Alvarez Quintero, intentan añadirle una forma más literaria que renueve el sainete y el entremés envolviendo la observación familiar de un discreto velo de poesía. Pero su difusión sería inexplicable si no reflejara un poco del genio nacional. Es evidente que no se ve ya en ella la imagen clara y vigorosa que dibujaron los poetas y artistas de la edad de oro. Los colores son deslustrados o falseados por barnizados extranjeros; es una mediocre cromolitografia, pero copia a veces, y a veces, recuerda el retrato magnífico en el que la España radiante se había reconocido y contemplado ${ }^{37}$.

Como varios de los periodistas franceses citados, Martinenche tiene una visión de España íntimamente relacionada con el pasado. Para él, la zarzuela lleva en sí, quizás por haber nacido en este perido, algo del Siglo de Oro. No podemos dejar de lado lo positivo de la palabra "poesía", con la cual asocia "la observación familiar". Con ella Martinenche llena de sentido la dimensión teatral de un género que describe las costumbres del pueblo español que conforma su público.

\footnotetext{
36 "Ce n'est pas plus bête, la musique de ces zarzuelas, que bien des choses chez nous. C'est même supérieur de style à nos opérettes et sonne mieux d'orchestre. Mais les livrets sont souvent le comble de la sottise", Le Ménestrel, 9-11-1928.

37 "Tour à tour romanesque et réaliste, satirique avec finesse, et grotesque jusqu'à la grossièreté, la zarzuela d'aujourd'hui nous présente, dans les contrastes qu'elle chérit, le miroir troublé du vieux génie espagnol. Il est rare assurément qu'elle ait une valeur artistique, et l'on ne saurait trop encourager les efforts de ceux qui, comme les frères Álvarez Quintero, cherchent à lui substituer une forme plus littéraire qui renouvelle le sainete et l'entremés en enveloppant l'observation familière d'un voile discret de poésie. Mais sa diffusion serait inexplicable si elle ne reflétait pas un peu du génie national. On n'y voit certes plus l'image nette et vigoureuse que tracèrent les poètes et les artistes de l'âge d'or. Les couleurs en sont ternies ou faussées de vernissages étrangers; c'est une médiocre chromolithographie, mais elle copie parfois et parfois elle rappelle le tableau magnifique où l'Espagne rayonnante s'était reconnue et contemplée". Ibid., p. 194.
} 
Si volvemos a enunciar los elementos que componen la definición de la voz "zarzuela", tendríamos: género poético y metáfora de la gloriosa pintura del Siglo de Oro en la cual España se autoretrataba. La proyección subjetiva de Martinenche revela una imagen de España en general -y de la zarzuela en particular- que forma parte de su identidad.

\section{Poético}

Al contrario que la prensa, el valor de la palabra poética no se refleja en la cantidad de veces que aparece el término, sino en su originalidad. Si ya nos hemos emocionado al encontrar la voz "zarzuela" en un libro de Gérard Genette, también produce cierto placer leerla en un poema de la obra de Valery Larbaud (1881-1957). El autor de la famosa novela Fermina Márquez y gran traductor compuso Les Poésies de A. O. Barnabooth en 1913, después de un viaje a través de Europa. Sin duda, su conocimento de la lengua española se refleja en la agudeza de su mirada a la hora de escribir sobre España. La palabra "zarzuela" se encuentra en un poema dedicado a las distintas voces femeninas que solía escuchar y que transcribimos en parte.

Oh, mais gonflez mon cœur de vos chansons, servantes!

Voix impériales, voix des filles du Sud!

Énergiques et graves comme les voix des garçons,

Vous vous mêlez à la chaleur et à l'air bleu,

À cette couronne que le soleil pose, là-haut, au mur aigu,

Cette bandelette orangée, aux confins des cieux, et que je vois

Levant la tête vers les abîmes éthérés.

Rythmant le travail, les airs en chœur,

Les vieilles scies, les refrains neufs;

Et les choses sentimentales de toujours:

La "Paloma" et "Llora, pobre corazón",

Les choses d'il y a dix ans, vous vous souvenez?

"Con una falda de percal blanca..."

(mon vieux cœur, tous nos beaux matins de la Navé!)

Les zarzuelas de l'an dernier, comme

"El arte de ser bonita" ou "La gatita blanca".

Écoutez ces furieuses, criant à grosse voix, l'air :

"Anteayer vi a una senora..."

(Vous vieillirez, refrains, et vous aussi, ô voix

Qui, pures, vous élancez de ces gorges charmantes!) ${ }^{38}$

En medio de la estrofa, Larbaud sitúa "las zarzuelas del año pasado", como una palabra familiar, sin voluntad de definirla. Ofrece dos ejemplos

38 Valery Larbaud: "Voix des servantes", A. O. Barnabooth, Poésies, 1913, pp. 40-41. 
concretos de 1905, El arte de ser bonita y La gatita blanca, ambas de Gerónimo Giménez y Amadeo Vives. De hecho, el verso "Anteayer vi a una señora" reproduce textualmente un verso cantado del cuadro segundo de El arte de ser bonita. Intuimos que Larbaud había asistido a varias representaciones y que no fueron las únicas zarzuelas a las que acudió. El poeta inserta la voz "zarzuela" para enardecer sus recuerdos y nutrirlos de elementos de una realidad vivida. Como muestran las distintas citas, estas vivencias dan acceso a un uso "desde dentro", in situ, en el que el poeta ofrece una muestra tan sugestiva que escuchamos las verdaderas voces que definen la zarzuela.

\section{Conclusión}

El uso y las definiciones de la palabra "zarzuela" en documentos en francés muestran varios fenómenos que, si bien conciernen a la palabra en sí, también revelan problemáticas más generales sobre el uso de extranjerismos y la dificultad de definir un género casi desconocido. Se destacan dos formas de tratar el problema: la primera, consiste en optar por la comparación con elementos autóctonos, que en el caso de la zarzuela son algunos géneros líricos franceses. Enseguida, observamos una tendencia muy clara en entradas de diccionarios y artículos de prensa: la definición es muy a menudo incompleta y, a veces, errónea, ya sea en medios antiguos o modernos. En varios casos, la exactitud, favorecida hoy por la circulación de trabajos universitarios e internet, cede paso a una subjetividad que se quiere imponer por la afición sincera al género de algunos autores. Esta figura del aficionado modifica en varias ocasiones la realidad descrita, pero el peso de su tradición tiene consecuencias. Es relevante que la palabra española se use sin traducción en francés: el aficionado es el digno heredero de viajeros extranjeros por España que posaron su mirada sobre cada objeto. En este caso, el amor mata. Al querer compartir el objeto del deseo, personas consideradas "autoridades" en su materia evitan que se emancipe y ocupe su lugar. La voz francesa "zarzuela", al fin y al cabo, no refleja el conocimiento de la zarzuela como género representado en varios escenarios franceses y estudiado en diversos trabajos universitarios franceses.

Este trabajo podría servir de punto de partida para un diagnóstico y reconocimiento que dé a conocer el género, porque "zarzuela", con o sin acento, no es aún un nom commun.

Recibido: 27-9-2018

Aceptado: 9-10-2018 

